\title{
Optimizing Nursing and Midwifery Practice in Rwanda
}

\author{
Andre Gitembagara ${ }^{1 *}$, Michael V. Relf ${ }^{2}$, Renee Pyburn ${ }^{3}$ \\ ${ }^{1}$ Rwanda Nurses and Midwives Union, Kigali, Rwanda, \\ ${ }^{2}$ Duke University School of Nursing, North Carolina, USA, \\ ${ }^{3}$ University of Rwanda College of Medicine and Health Sciences
}

\begin{abstract}
Following the 1994 genocide in Rwanda, the number of nurses remaining in practice in Rwanda was critically low. Since that time the leaders of Rwanda have worked diligently to increase both the number of nurses in Rwanda and their level of education. They have also set goals for the number of healthcare workers that should be in each facility according to the population in the catchment area. In 2015, a cross sectional, descriptive study was done to evaluate the gaps between the targeted number of the nurses and midwives in the health centers and district hospitals in Rwanda and the actual numbers in these facilities. Results indicated that in health centers staffing levels were at 55\% of recommended levels, and in district hospitals $80.5 \%$ of recommended staffing levels. Looking to the future, Rwanda must focus not only on staffing numbers but also evaluate the practice environment, healthcare system, and the roles and responsibility of nurses and midwives. Education systems must also prioritize ensuring that entry-level nurses and midwives enter into the profession with essential competencies for safe practice, that interdisciplinary team practice is a part of the curriculum, and that nurses and midwives are educated beyond the associate nurse level.
\end{abstract}

Keywords: Rwanda, nursing practice, midwifery practice, nurse staffing, East Africa

\section{Introduction and Background}

Historical records show that 983 nurses were qualified in Rwanda just immediately prior to the Tutsi genocide of 1994. In December 1994, after the genocide, only 346 nurses remained (Rwanda $\mathrm{MoH}$ annual report, 1999). In the last two decades, leaders of Rwanda have worked diligently to build human resources and infrastructure to provide health services to Rwandan citizens. Currently there are 11,500 applicants in the National Council of Nurses and Midwives (NCNM) (all categories) but only 6,000 are licensed to practice. Table 1 below shows the Nursing and Midwifery achievements since 1995 to 2015:

Table 1. Nursing and midwifery progress from 1995 to 2015

\begin{tabular}{|c|c|}
\hline Education & Regulations and advocacy \\
\hline $\begin{array}{l}\text { - Since 1995, establishment of } 30 \text { secondary schools of asso- } \\
\text { ciate/enrolled nurses (phased out in 2007) }\end{array}$ & $\begin{array}{l}\text { Establishment of National Council of Nurses and Midwives by } \\
\text { law number } 25 / 2008 \text { of } 25 \text { th July } 2008 \text { with mandate to work } \\
\text { on educational standards, code of conduct, scope of practice, } \\
\text { provide license to practice, etc. }\end{array}$ \\
\hline $\begin{array}{l}\text { - 1997-starting of nursing and midwifery diploma level school } \\
\text { in former KHI } \\
\text { - Since } 2007 \text {, establishment of } 5 \text { other public schools of nurs- } \\
\text { ing and midwifery for diploma level }\end{array}$ & $\begin{array}{l}\text { - A Chief Nursing Office has been established after genocide for } \\
\text { planning and monitoring of nursing and midwifery activities }\end{array}$ \\
\hline $\begin{array}{l}\text { - Nowadays, } 1 \text { public and } 2 \text { private schools are training at } \\
\text { Bachelor's education level }\end{array}$ & $\begin{array}{l}\text { - A Nurses and Midwives Association was created in } 1996 \text { and } \\
\text { transformed into a trade union in } 2013 \text { called Rwanda Nurses } \\
\text { and Midwives Union (RNMU), which is a professional advocacy } \\
\text { and labor organization. }\end{array}$ \\
\hline $\begin{array}{l}\text { - Masters level training for some specialties currently in de- } \\
\text { velopment }\end{array}$ & \\
\hline
\end{tabular}

Source: Nursing and Midwifery Personnel Plan-2009 Policy

*Corresponding author: gandreza@yahoo.fr 
In September 2009, the Ministry of Health established norms and policies designed to increase the number of skilled health workers in service and to improve equitable distribution (Rwanda $\mathrm{MoH}, 2009$ ). This important policy established parameters to define the number of health personnel that should be in each health facility according to the population in the catchment area. Further, the number was also defined according to the minimum package of activities delivered at each level. For example, the 2009 guidelines specified that a health center with catchment area covering 20,000 in population should have 18 nurses/midwives. At a district hospital, serving a catchment area of 200,000 persons, the guidelines specified that 63 nurses/midwives should be allocated.

\section{Methods}

To determine the current state of nursing and midwifery workforce staffing in relation to the 2009 Rwanda MOH guidelines, the Rwandan Nursing and Midwifery Union designed and funded a cross sectional, descriptive study occurring in January 2015.

The study aimed to evaluate the achievements and gaps of the nursing and midwifery workforce in Rwandan health centers (HCs) and district hospital (DHs). The specific aims of this study were to (1) determine the number of nurses/midwives allotted to health facilities, and (2) evaluate the achievement in terms of nursing/midwifery personnel in accordance with the $2009 \mathrm{MOH}$ guidelines.

Of the 461 health centers in Rwanda, stratified sampling method by province was done yielding 40 health centers for inclusion in the study. The 40 health centers were stratified as follows: Eastern province, 10; Northern province, 7; Southern province, 11; Western province, 8; and Kigali City, 4. Of the 42 district hospitals in Rwanda, 21 were randomly sampled. One hospital had missing data elements and could not be included in the study. Thus, 20 district hospitals were included in the study and geographically represented as follows: Eastern province, 3; Northern province, 4; Southern province, 5; Western province, 6; and Kigali City, 2. Table 2 provides further information about the district hospitals and their locations utilized for data collection.
Table 2. List of 20 district hospitals and their locations

\begin{tabular}{|l|l|}
\hline Province & Hospital \\
\hline Eastern & Kiziguro \\
& Nyamata \\
& Rwamagana \\
\hline Northern & Byumba \\
& Butaro \\
& Nemba \\
& Ruhengeri \\
\hline Southern & Ruhango \\
& Kamonyi \\
& Nyanza \\
& Kaduha \\
& Kibilizi \\
\hline Western & Gisenyi \\
& Kibogora \\
& Kirinda \\
& Mugonero \\
& Kibuye \\
& Shyira \\
\hline Kigali City & Kibagabaga \\
& Masaka \\
\hline
\end{tabular}

\section{Results}

The 40 health centers sampled for our study served a population of 928,721 persons. According to the $2009 \mathrm{MOH}$ guidelines, the health centers should have been staffed with 836 nurses/midwives. Analysis of workforce data revealed that there were 459 nurses/midwives assigned to the 40 health centers yielding $55 \%$ of the recommended staffing coverage. Further analysis documented that at the health center level, $29.3 \%$ of the health centers were staffed at levels $<50 \%$ of the recommended guidelines for nurses/midwives, $46.3 \%$ were staffed between $50 \%$ and $74 \%, 19.5 \%$ were staffed at levels between $75 \%$ and $100 \%$ of guidelines, and $4.9 \%$ were staffed at levels above the standards. The percentage of licensed nurses and midwives was $27.02 \%$, and the percentage of non-licensed nurses and midwives was $72.98 \%$.

At the district hospital level, the 20 institutions sampled for this study served a population of 5,789,692 persons. According to the $2009 \mathrm{MOH}$ guidelines, the district hospitals should have been staffed with 1824 nurses/midwives. Analysis of workforce data revealed that there were 1468 nurses/midwives assigned to the 20 district hospitals yielding $80.5 \%$ of the recommended staffing coverage. Further analysis documented that at the district hospital level $4.8 \%$ 
were staffed at levels $<50 \%$ of the recommended guidelines for nurses/midwives, $28.6 \%$ were staffed between $50 \%$ and $74 \%, 47.6 \%$ were staffed at levels between $75 \%$ and $100 \%$ of guidelines, and $19 \%$ were staffed at levels above the standards. Fifty seven per- cent were not licensed, and $43 \%$ were licensed.

Current level of coverage of nurses and midwives in health centers and district hospitals compared to the level recommended by the Ministry of Health is shown in Fig. 1.

\section{Nursing \& Midwifery Staffing Levels at Health Centers and District Hospitals: Adequacy of Staffing in relation to $\mathrm{MOH}$ recommended Staffing Guidelines}

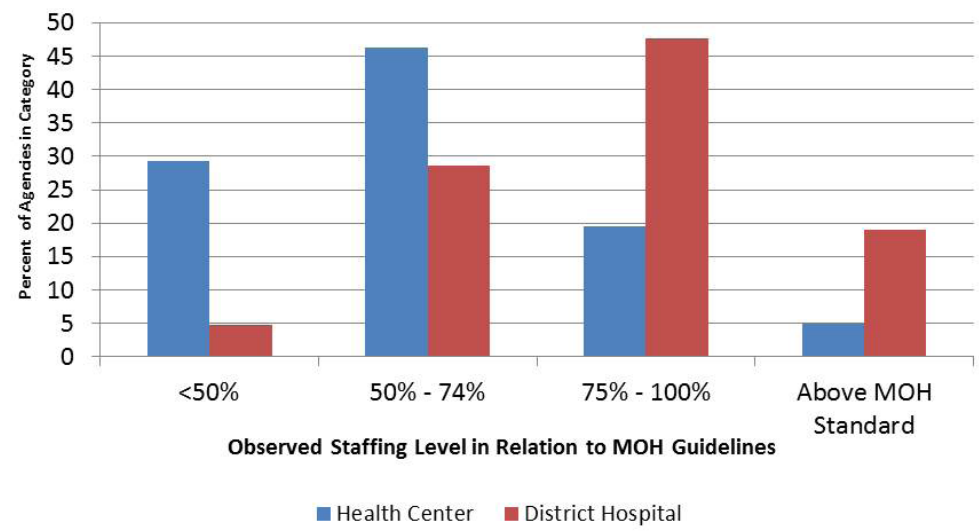

Figure 1. Proportion of nurses and midwives relative to MoH standards

\section{Discussion and Looking Forward}

According to the $\mathrm{MOH}$ standards for the nursing and midwifery workforce at the district hospital level, the current level of staffing is at $80.5 \%$ of the recommended level. In the healthcare centers it is lower at only $55 \%$ of the recommended level. With continued commitment to expanding access to nursing and midwifery education, it will be possible to achieve the $2009 \mathrm{MOH}$ of staffing guidelines.

The level of licensing is still low at both the healthcare center and district hospital level at $27 \%$ and $57 \%$, so there is still a need for considerable improvement in this area as the goal is for all nurses and midwives to be licensed.

Rwandans have benefited from rapid economic growth, reduced poverty, more equality and increased access to services including health and education. This has been possible only through the hard work and dedication of millions of Rwandans supported by friends of Rwanda (The Republic of Rwanda EDPRSII, 2013; Government of Rwanda, 2012). This progress strengthens the belief that the development ambitions towards the Vision 2020 can be achieved with concerted efforts. The EDPRII is focused on ensuring that poverty is reduced from $44.9 \%$ in 2013 to below 30\% by 2018 .
However, to improve patient outcomes, it is critical to look beyond just the minimum staffing number of nurses and midwives allocated to the health centers and district hospitals. In 2010, the World Health Organization published the Workload indicators of staffing need, user's manual (WHO, 2010). This document highlighted that it is not only essential to have the right number of people, but it is also essential to ensure that the right people have the right skills, are in the right place, at the right time, with the right attitude, doing the right work, at the right cost, with the right work output. These "rights of staffing" provide a more comprehensive framework for analyzing staffing. By using this framework, the Rwandan nursing and midwifery professions, in partnership with the Ministry of Health, can collaborate to improve patient outcomes, efficiently utilize valuable resources, and improve job satisfaction and ultimately retention of nurses and midwives in Rwanda.

These "rights of staffing" can provide guidance not only to government, but also educators and managers of nurses and midwives. In order for the right nurse or midwife to have the right skills, it is necessary to systematically and periodically evaluate the practice environment, the health care delivery system, and the roles and responsibilities expected of the nurse or midwife. Through this formal evaluation, it can be 
determined who should be doing the right work in an era of task shifting/task sharing. Further, systematic and periodic evaluation of the practice environment can also determine not only the necessary skillset needed by nurses and midwives but also the necessary knowledge and abilities. Collectively, knowledge, skills and abilities, better known as competencies (ICN, 2008), should guide pre-service, and in-service education. Educational redesign to focus on competencies will better enable nurses and midwives to have the essential competencies to engage in clinical decision making, prioritization of patient care, interdisciplinary collaboration, and leadership at the bedside or in the community upon entry into practice.

Further, in regards to pre-service education, to ensure that nurses and midwives enter into practice with the essential entry level competencies required for safe practice, there must be a radical shift in the pedagogical approaches used to prepare these practitioners (Benner, Sutphen, Leonard \& Day, 2010). First, the days of faculty directing student learning focusing on memorization must cease. Instead, the teaching-learning environment must shift to foster clinical decision making and prioritization of care. Second, the respective disciplines involved in health care cannot continue to be educated in isolation. Clinical practice requires interdisciplinary collaboration to ensure patient safety and optimal patient outcomes.Therefore, nurses, midwives, physicians, pharmacists, physiotherapists and other essential members of the health care team should be educated together in the classroom and practice clinically as students in a team-based learning environment under the guidance of expert clinicians who are also master educators.

This study revealed also an issue of inequity distribution of human resources in nursing and midwifery. To ensure that nurses and midwives have the right attitudes for practice, numerous strategies can be implemented to promote a healthy work environment. First, all practitioners should be valued and respected for the disciplines' unique perspectives and contributions to patient care. When a member of the interdisciplinary team is treated as "just a nurse" or "just a midwife", the devaluing frequently results in decreased job satisfaction and staff turnover. Second, as nurses and midwives educationally advance, instead of being directed into managerial or educational positions, the government and the practice environments could develop clinical ladders allowing those individuals wanting to stay at the bedside or in the community to do so. Clinical leaders are still an issue in Rwandan health facilities since the majority of directors of nursing, heads of health centers, and heads of units are educated at the level of associate/ enrolled nurse.

To contribute to achieving the country's vision 2020 and EDPRS II, the Ministry of Health is committed to improving the quality, demand and accessibility of primary health care. The Government of Rwanda's goal is to improve the quality of health care services, including the management of hospitals, while continuing to expand geographical and financial accessibility (EDPRS II, 2013). Developing Human Resources for Health (HRH) in quantity and quality to respond to the needs and rational distribution based on norms strengthens the performance of the training institution. Currently, a large number of nurses are leaving the nursing profession for other professions and complaining about heavy workloads, a disadvantage in career development, and a lack of access to courses to upgrade their knowledge. Nursing education has for many years been training only associate nurses. It is only after the genocide that the first school for nursing and midwifery was created, producing a small number of nurses and midwives. Currently, the Government of Rwanda is initiating the program of upgrading A2 (associate) nurses to the level of A1 (diploma) nurses or midwives with an e-learning program. There are six public schools of nursing and midwifery and two private schools to train Registered Nurses. All A2 training schools were phased out in 2007.

Whilst in this study district hospitals seem to be well staffed in nursing and/or midwifery at $80 \%$ (which shows the large effort of the Government to cover the required number), the health centers are staffed at a low level of $55 \%$. Both health centers and district hospitals are affected by the issue of staff sustainability since some of them are working under end term project contracts which may close with project end dates. Some nurses have already been affected by this issue.

Furthermore, upgrading the education program from associate (enrolled) nurses to the level of registered nurses or midwives may also affect the existing low numbers in health facilities. Health facilities are not able to replace those who are attending schools for approximately three years to upgrade their level 
of education. To cover the gap in staffing numbers, most of the nurses and midwives in health centers are required to work more than 45 hours a week, which may affect the quality of care provided to the patient population.

\section{Conclusion}

Although Rwanda has made huge strides in improving both the numbers of nurses and midwives in practice and their level of education, much work still remains to be done. Levels of staffing in both health centers and district hospitals are below recommended government guidelines, especially in health centers, and the percentage of registered nurses and midwives remains low at only $27.02 \%$ in health centers and $43 \%$ in district hospitals. Education should move towards a competency-based framework, and include team-based interprofessional education. Improvements in staffing levels and working conditions, continuing education opportunities, and professional development need to be provided in order to improve retention of nurses and midwives.

When all members of the health care team are respected for their unique competencies and contributions, and when education and clinical care is delivered in a collaborative environment, patient outcomes are ultimately improved - the ultimate goal of health care. A joint analytical study by relevant actors in nursing and midwifery is recommended to analyze the association between the number of nurses or midwives with the quality of care they are providing in Rwanda to come up with relevant recommendations to the Government.

\section{References}

Benner, P., Sutphen, M., Leonard, B., \& Day, L. (2010). Educating nurses: A call for radical transformation. San Francisco, CA: Jossey-Bass.

Government of Rwanda (MoH). (2012). Third Rwanda bealth sector strategic plan July 2012 - June 2018. Kigali, Rwanda: Author.

International Council of Nurses (ICN). (2008). Nursing care continuum: Framework and competencies. Geneva, Switzerland: International Council of Nurses.

Rwanda MoH. (2009). Politiques et normes de services de santé, normes relatives au personnel de: Umudugudu, Poste de Santé Communautaire, Centre de Santé, Hôpital de District. Kigali, Rwanda.

Rwanda MoH. (1999). Rapport annuel 1999. Kigali, Rwanda: Author.

Rwanda Nurses and Midwives Association. (2012). Rwanda Nurses and Midwives Association: Nurses and midwives needs assessment survey. Kigali, Rwanda: Author.

The Republic of Rwanda. (2013). The Republic of Rwanda (EDPRSII): Rwanda economic development and poverty reduction strategy 2013 - 2018. Kigali, Rwanda: Author.

World Health Organization. (2010). Workload Indicators of staff need, user's manual. Geneva, Switzerland: WHO Press. 